\title{
Evidence of cyanobacteria-like endosymbionts in Acroporid corals from the Great Barrier Reef
}

Received: 24 December 2008/Accepted: 26 January 2009/Published online: 13 February 2009

(C) Springer-Verlag 2009

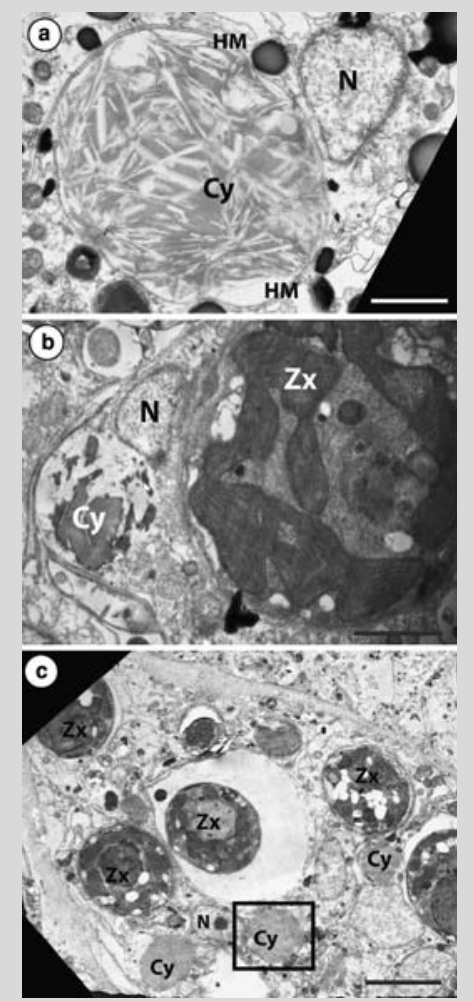

Fig. 1 Representative transmission electron microscopy photographs, (a) intracellular cyanobacteria-like cell enclosed in a host membrane (scale bar $=1 \mu \mathrm{m}$ ), (b) Symbiodinium and cyanobacteria-like structure within a single host cell (scale bar $=2 \mu \mathrm{m}$ ), (c) overview of Symbiodinium and cyanobacteria-like cells in the host gastroderm (scale bar $=4 \mu \mathrm{m})$. Key: cyanobacteria-like structures $(C y)$, host nucleus $(N)$, Symbiodinium $(Z x)$, host membrane $(H M)$
The coral host is associated with a diverse microbial community, including zooxanthellae, bacteria, protists, fungi and algae (Rohwer et al. 2002). Lesser et al. (2004) describe a novel cyanobacterial endosymbiont in the Caribbean coral Montastraea cavernosa capable of nitrogen fixation. Evidence is now presented from transmission electron microscopy of similar cyanobacteria-like cells from two species of tabular Acroporid (Acropora hyacinthus and Acropora cytherea) from the Heron and Wistari Reefs (southern Great Barrier Reef).

These intracellular cyanobacteria-like structures were characterised by irregular layered thylakoid membranes (Fig. 1a), and bear remarkable similarity to those described by Lesser et al. (2004). The cells were consistent in size $(1-4 \mu \mathrm{m})$ and enclosed in an apparent host membrane (Fig. 1a). In several samples, cyanobacteria-like structures were observed adjacent to Symbiodinium within a single host cell (Fig. 1b) and were often in high densities throughout the gastrodermal tissues (Fig. 1c). The implications of such high densities and close association of these cyanobacterialike structures and Symbiodinium are considerable, considering that Symbiodinium preferentially uptake the products of nitrogen fixation over host tissues (Lesser et al. 2007).

These cyanobacteria-like cells were observed in 14 out of 16 samples collected in both summer (March) and winter (July) months of 2004, implying temporal stability of the association. These observations expand upon previous reports of intracellular cyanobacteria from the Caribbean region (Lesser et al. 2004) and suggest that this association may be more widespread than previously assumed. Further research is currently being conducted to determine the taxonomic identity of these structures and the implications for intracellular nitrogen fixation in Indo-Pacific Acroporids.

\section{References}

Lesser MP, Mazel CH, Gorbunov MY, Falkowski PG (2004) Discovery of nitrogenfixing cyanobacteria in corals. Science 305:997-1000

Lesser MP, Falcón LI, Rodríguez-Román A, Enríquez S, Hoegh-Guldberg O, Iglesias-Prieto R (2007) Nitrogen fixation by symbiotic cyanobacteria provides a source of nitrogen for the scleractinian coral Montastraea cavernosa. Mar Ecol Prog Ser 346:143-152

Rohwer F, Seguritan V, Azam F, Knowlton N (2002) Diversity and distribution of coral-associated bacteria. Mar Ecol Prog Ser 243:1-10

E. C. E. Kvennefors $(\bowtie) \cdot$ G. Roff

ARC Centre of Excellence for Coral Reef Studies, Centre for Marine Studies, University of Queensland, 4072 Brisbane, QLD,

Australia

e-mail: c.kvennefors@uq.edu.au

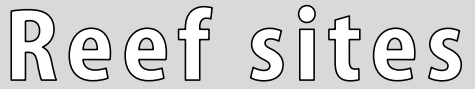

Coral Reefs (2009) 28:547

DOI $10.1007 / \mathrm{s} 00338-009-0473-0$ 